\title{
In Silico Assessment of Adverse Effects of a Large Set of 6-Fluoroquinol- ones Obtained from a Study of Tuberculosis Chemotherapy
}

\author{
Marjan Tušar, Nikola Minovski, Natalja Fjodorova and Marjana Novič
}

National Institute of Chemistry, Hajdrihova 19, SI-1001 Ljubljana, Slovenia

\begin{abstract}
Among the different chemotherapeutic classes available today, the 6-fluoroquinolone (6-FQ) antibacterials are still one of the most effective cures in fighting tuberculosis (TB). Nowadays, the development of novel 6-FQs for treatment of TB mainly depends on understanding how the structural modifications of the main quinolone scaffold at specific positions affect the anti-mycobacterial activity. Alongside the structure-activity relationship (SAR) studies of the 6-FQ antibacterials, which can be considered as a golden rule in the development of novel active antitubercular 6-FQs, the structure side-effects relationship (SSER) of these drugs must be also taken into account. In the present study we focus on a proficient implementation of the existing knowledge-based expert systems for design of novel 6-FQ antibacterials with possible enhanced biological activity against Mycobaterium tuberculosis as well as lower toxicity. Following the SAR in silico studies of the quinolone antibacterials against $M$. tuberculosis performed in our laboratory, a large set of 6-FQs was selected. Several new 6-FQ derivatives were proposed as drug candidates for further research and development. The 6FQs identified as potentially effective against $M$. tuberculosis were subjected to an additional SSER study for prediction of their toxicological profile. The assessment of structurally-driven adverse effects which might hamper the potential of new drug candidates is mandatory for an effective drug design. We applied publicly available knowledge-based (expert) systems and Quantitative Structure-Activity Relationship (QSAR) models in order to prepare a priority list of active compounds. A preferred order of drug candidates was obtained, so that the less harmful candidates were identified for further testing.

TOXTREE expert system as well as some QSAR models developed in the framework of EC funded project CAESAR were used to assess toxicity. CAESAR models were developed according to the OECD principles for the validation of QSAR and they turn to be appropriate tools for in silico tests regarding five different toxicity endpoints. Those endpoints with high relevance for REACH are: bioconcentration factor, skin sensitization, carcinogenicity, mutagenicity, and developmental toxicity. We used the above-mentioned freely available models to select a set of less harmful active 6-FQs as candidates for clinical studies.
\end{abstract}

Keywords: Tuberculosis, antibacterial drugs, predictive models, new active molecules, assessment of toxicity.

\section{INTRODUCTION}

Nowadays, the treatment of tuberculosis (TB) mostly relies on 6-fluoroquinolone (6-FQ) antibacterials. By 1962, George Lesher and colleagues developed nalidixic acid, the first clinically useful quinolone (Scheme 1a) [1]. Koga et al. [2] improved absorption and activity by making modifications at positions $\mathrm{C} 6$ of the pharmacophore. Afterwards molecules with fluorine atom at C6 called 'fluoroquinolones' are among the most intensively investigated group of compounds in the field of medicinal chemistry (Scheme 1b) [3].

The high antibacterial potency of fluoroquinolone derivatives is often accompanied by the undesirable adverse effects that have to be studied in the early stage of the drug design process in order to avoid high costs of later in vivo studies. Some of the various structural modifications, which have provided the increased antibacterial activity and efficacy, have also resulted in an increased toxicity as highlighted in a review of the structure-activity and structure side effect relationships for the quinolones by Domagala et al.

*Address correspondence to this author at the National Institute of Chemistry, Hajdrihova 19, SI-1001 Ljubljana, Slovenia; Tel: +386 14760 253; Fax: +386 14760 300; E-mail: marjana.novic@ki.si
[4]. One of the major reasons of the two significant sideeffects of the quinolone antibacterials, phototoxicity and in vitro genetic toxicity, is the substituent at C8, see Scheme 1b. The highest phototoxicity is observed when the substituent is halogen, and the lowest when the substituent is $\mathrm{O}$-alkyl, with the order of decreasing phototoxicity as $\mathrm{CF}>$ $\mathrm{CCl}>\mathrm{N}>\mathrm{CH}>\mathrm{CCF} 3>\mathrm{COR}[5,6]$.

In this study we have employed in silico models and freely available online tools to assess potential adverse effects of 133 new drug candidates. They were identified as hit molecules by a previously developed quantitative structure-activity relationship (QSAR) model, based on a set of 145 different 6-FQ derivatives with known experimentally-determined biological activity.

\section{DATABASE}

6-Fluoroquinolone Compound Library-Virtual Generation and In Silico Characterization

During the past 50 years, series of 6-FQ antibacterials have been synthesized and evaluated for their antimycobacterial activity [6]. For the majority of them the influence of the substructural alterations on specific positions within the 6-FQs scaffold on the antibacterial 


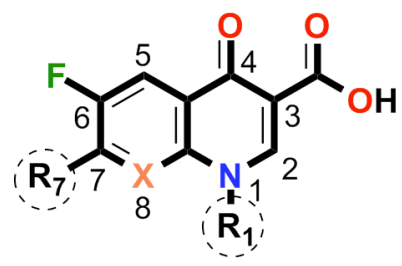

$$
\begin{aligned}
& \mathbf{R}_{\mathbf{1}}=\text { usually cyclopropyl } \\
& \mathbf{R}_{\mathbf{7}}=\text { heterosystem } \\
& \mathbf{X}=\mathrm{N}, \mathrm{C}
\end{aligned}
$$

Scheme 1. Quinolone antibacterials: a) Nalidixic acid; b) generic structure of 6-fluoroquinolone (6-FQ) derivatives.

potency can be evaluated only with in silico QSAR studies $[7,8]$. Following the existing structure-activity relationship (SAR) recommendations for the 6-FQ antibacterials [7], a comprehensive and robust in silico study of their antibacterial activity against $M$. tuberculosis was performed. For that purposes, a set of $1456-\mathrm{FQ}$ antibacterials with experimentally determined biological activity values (expressed as minimal inhibitory concentration, MIC $[\mu \mathrm{g} / \mathrm{mL}])$ [9] was initially used for building a counterpropagation artificial neural network (CP ANN) predictive model [10]. On the other hand, a mixed virtual combinatorial dataset of total 427 structurally similar 6-FQ drug-like compounds $\left(\mathrm{R}_{1}, \mathrm{R}_{7^{-}}\right.$structural analogs of ciprofloxacin and moxifloxacin, and $R_{7}$-structural analogs of ofloxacin) was constructed by using a combinatorial library design approach in virtual space $[11,12]$. All combinatorial 6-FQ compounds (1.101 compounds) were used afterwards as an external dataset for prediction of their biological activity values ( $\left.\mathrm{MIC}_{\text {pred-combi }}[\mu \mathrm{g} / \mathrm{mL}]\right)$ through the utilization of our constructed CP ANN predictive model. Furthermore, the combinatorial 6-FQ compounds identified as potentially active against $M$. tuberculosis (427 compounds; $0.00 \leq$ $\mathrm{MIC}_{\text {pred-combi }}[\mu \mathrm{g} / \mathrm{mL}] \leq 1.00$ ) were additionally evaluated in a molecular docking study - estimation of their binding affinity within a $M$. tuberculosis DNA gyrase binding site model [12]. This procedure revealed a focused set of total 133 novel combinatorially-generated 6-FQ derivatives as potential drug candidates for further research and development [12]. On both sets of 6-FQs the structure sideeffects relationship (SSER) study for prediction of their toxicological profile was performed. Structurally-driven adverse effects might hamper the potential of new drug candidates. We applied publicly available knowledge-based expert systems and QSAR models in order to identify less toxic compounds among the drug candidates. The resulting priority list of active compounds specifies the preferred order in which the less harmful candidates should be favored for further testing.

\section{CAESAR PREDICTION MODELS}

CAESAR was an EC funded project (Project no. 022674 - SSPI), which was specifically dedicated to develop QSAR models for the REACH legislation [13]. Five endpoints with high relevance for REACH have been addressed within CAESAR, namely bioconcentration factor, skin sensitization, carcinogenicity, mutagenicity, and developmental toxicity.

CAESAR models have been assessed according to the OECD principles for the validation of QSAR. For the model validity a wide series of statistical checks was used. With the external tests it was verified that the models perform correctly on new compounds, as well. The Carcinogenicity
Classification Model has been built as CP ANN model [14]. Neural network model provides a qualitative prediction of carcinogenic potency according to specific requirements of Chemical regulation. Models for five endpoints developed within CAESAR project are available at Caesar project web page [15], and VEGA web page [16].

\section{VEGA PLATFORM}

VEGA is a tool supporting the human expert in the assessment of the chemical properties. It combines QSAR and read-across tools [17]. The QSAR prediction is based on CAESAR or T.E.S.T. models. Read-across algorithm shows similar compounds, assesses the QSAR results on the similar compounds, and analyzes some relevant chemical features in the target compound and its related compounds. Some automatic evaluation for read-across is done, however the user should analyze the results also independently.

Using the VEGA platform, one can access a series of QSAR models for regulatory purposes as follows:

1. LogP model: The prediction is made using two wellknown molecular descriptors: ALogP and MLogP. $\mathrm{ALog} \mathrm{P}$ is the Ghose-Crippen-Viswanadhan $\log \mathrm{P}$ and consists of a regression equation based on the hydrophobicity contribution of 120 atom types. MLogP is the Moriguchi $\log P$ and consists of a regression equation based on 13 structural parameters. The produced value is the arithmetic mean of the two calculated descriptors; the difference between these two values is taken into account for evaluating the reliability of the prediction.

2. Bioconcentration factor (BCF) model: The model provides a quantitative prediction of bioconcentration factor (BCF) in fish. Model A and Model B, have been used to build hybrid model, Model C. The outputs of the individual models (Model A and B) are used as inputs of the hybrid model. Model A is developed by Radial Basis Function Neural Networks (RBFNN) using a heuristic method to select the optimal descriptors; Model B is developed by RBFNN using genetic algorithm for the descriptors selection.

3. $\mathrm{LC}_{50}$ model: The model provides a quantitative prediction for fathead minnow (Pimephales promelas) $\mathrm{LC}_{50}$ (96 hour). The model is a reimplementation of the original model developed by Todd Martin inside T.E.S.T. software.

4. Carcinogenicity Classification Model: The model provides a qualitative prediction of carcinogenic potency for rats. It has been built as a Counter Propagation Artificial Neural Network (CP ANN). 
The neural network output consists of two values labeled as Positive and Non-Positive, both in the range $[0,1]$ and with sum equal to 1 ; they represent the probability of the hit compound to belong to the carcinogenic or non-carcinogenic class of compounds. The higher of the two values determines the prediction. After obtaining the prediction from the CPANN model, some Structural Alerts are checked and if some matches are found, a remark is given about the presence of some fragments related to a possible carcinogenic activity.

5. Mutagenicity Classification Model: The model provides a qualitative prediction of mutagenicity on Salmonella typhimurium (Ames test). An integrated model was built cascading two models: Model A, a trained Support Vector Machine (SVM) classifier, and an additional Model B for false negatives removal based on Structural Alerts [18]. Model B works with two sets of Structural Alerts: the first one is related to mutagenicity; if no matching is found the second set is checked, and if some matches are found, the prediction is "suspect mutagen".

6. Developmental Toxicity Classification Model: The model provides a qualitative prediction of developmental toxicity, based on a binary classification of FDA criteria (FDA categories A and $\mathrm{B}$ are considered as non-toxicant, categories $\mathrm{C}, \mathrm{D}$ and $\mathrm{X}$ are considered toxicant). The model is a QSAR classification model based on a Random Forest method.

7. Skin Sensitisation Model: The model provides a qualitative prediction of skin sensitisation on mouse. QSAR models can be used to predict the property of a chemical compound, using information obtained from its structure. Model consists in an Adaptive Fuzzy Partition (AFP).

\section{TOXTREE EXPERT KNOWLEDGE SYSTEM}

TOXTREE is a software application, which is able to estimate toxic hazard by applying a decision tree approach. TOXTREE was developed by Ideaconsult Ltd (Sofia, Bulgaria). The software is made freely available as a service to scientific researchers and anyone with an interest in the application of computer-based estimation methods in the assessment of chemical toxicity.

TOXTREE expert (knowledge) system was used in our study to check the toxicity of obtained compounds. Cramer classification scheme (or tree) based on the Threshold of Toxicological Concern (TTC) concept was applied. In the application of the TTC concept to non-cancer endpoints, the decision tree is probably the most widely used approach for classifying and ranking chemicals according to their expected level of oral systemic toxicity.

The tree relies primarily on chemical structures and on estimates of total human intake to establish priorities for testing. This scheme is based on recognized pathways for metabolic deactivation and activation, toxicity data etc. The more detailed information can be found in [19-21]. The decision tree categorizes chemicals into three classes indicating three level of concern: high (Class III), medium (Class II) and low (Class I). Class III represents substances with chemical structures that permit no strong initial presumption of safety or may even suggest significant toxicity or have reactive functional groups. Class II contains substances with structures that are less innocuous than class I substances, but do not contain structural features suggestive of toxicity like those substances in class III. Class I represents substances with simple chemical structures and for which efficient modes of metabolism exist, suggesting a low order of oral toxicity. Each Cramer class is associated with a specified human exposure level, below which chemicals are considered to present a negligible risk to human health. In the absence of experimental hazard data, these exposure threshold (TTC) values have formed the basis of priority setting in the risk assessment process. The details are given in the reference [20].

\section{RESULTS}

\section{Vega Platform}

An extensive report was obtained with VEGA platform when a set of 145 6-FQs with experimentally-determined antibacterial activity was tested for the toxic effects. We concentrated on predicted skin sensitization, carcinogenicity, mutagenicity, and developmental toxicity. The results are presented in Table 1, along with the information of the experimental activity and chemical structure. There was only one compound in this data set with prediction for all toxicity parameters to be negative, i.e. non toxic. Additional 18 compounds were predicted as non-toxic for all endpoints except for one, as can be seen from Table 1. It was expected that major contributors to phototoxicity and in vitro genetic toxicity should be the substituent at X8 (Scheme 1b), with the order of decreasing effect as $\mathrm{CF}>\mathrm{CCl}>\mathrm{N}>\mathrm{CH}>$ CCF3 $>$ COR $[5,6]$. From results in Table 1 it can be seen that low toxicity was predicted for the compounds with several different substituent at $\mathrm{X} 8$ (Scheme 1b), such as $\mathrm{COH}, \mathrm{CCl}, \mathrm{CF}, \mathrm{N}, \mathrm{CH}$, not all in the expected order. The reason for this may be in the influence of more than one substituent on the same 6-FQ molecule. The advantage of the VEGA platform based on the statistical models is in dealing with every molecule as a whole, taking into account the effects of all the substituents on each 6-FQ molecule. When testing the accuracy and reliability of the toxicity prediction results, practically all selected compounds with low toxicity have poor scoring for the model applicability domain, which decrease the reliability, but not necessarily the accuracy of the predictions. For a few predicted values from mutagenicity classification model we obtained slightly better, i.e. "moderate reliability". In VEGA platform moderate reliability mark means that the compound might be out of the model applicability domain. Accuracy is determined with accuracy prediction for similar molecules found in the training set. For most of the molecules from a set of 145 6-FQs with experimentally determined antibacterial activity we found that the accuracies of models are good, or in some cases the accuracy of prediction for similar molecules found in the training set is not optimal. Only some accuracies from developmental toxicity model 
Table 1. Compounds with at Most One Positive Toxicity Predicted by VEGA Platform from the Set of 145 6-FQs with Experimentally-Determined Antibacterial Activity $\left(\mathrm{MIC}_{\exp }[\mu \mathrm{g} / \mathrm{mL}]\right)$

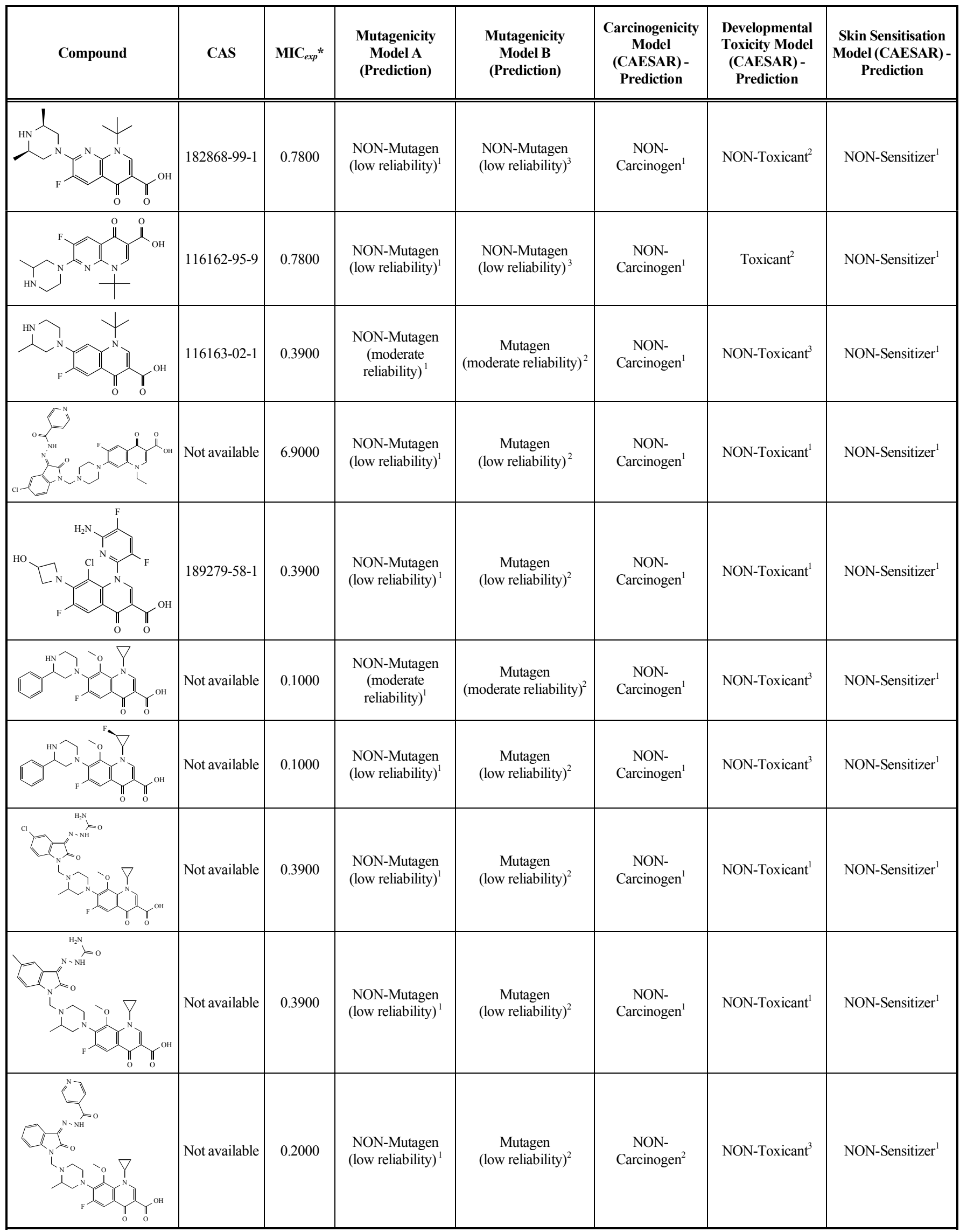




\begin{tabular}{|c|c|c|c|c|c|c|c|}
\hline Compound & CAS & $\mathbf{M I C}_{e x p} *$ & $\begin{array}{c}\text { Mutagenicity } \\
\text { Model A } \\
\text { (Prediction) }\end{array}$ & $\begin{array}{l}\text { Mutagenicity } \\
\text { Model B } \\
\text { (Prediction) }\end{array}$ & $\begin{array}{c}\text { Carcinogenicity } \\
\text { Model } \\
\text { (CAESAR) - } \\
\text { Prediction }\end{array}$ & $\begin{array}{l}\text { Developmental } \\
\text { Toxicity Model } \\
\text { (CAESAR) - } \\
\text { Prediction }\end{array}$ & $\begin{array}{l}\text { Skin Sensitisation } \\
\text { Model (CAESAR) - } \\
\text { Prediction }\end{array}$ \\
\hline & Not available & 0.3900 & $\begin{array}{l}\text { NON-Mutagen } \\
\text { (low reliability) }^{1}\end{array}$ & $\begin{array}{c}\text { Mutagen } \\
\text { (low reliability) }\end{array}$ & $\begin{array}{c}\text { NON- } \\
\text { Carcinogen }\end{array}$ & NON-Toxicant ${ }^{1}$ & NON-Sensitizer ${ }^{1}$ \\
\hline & Not available & 0.7800 & $\begin{array}{l}\text { NON-Mutagen } \\
\text { (low reliability) }^{1}\end{array}$ & $\begin{array}{c}\text { Mutagen } \\
\text { (low reliability) }^{2}\end{array}$ & $\begin{array}{c}\text { NON- } \\
\text { Carcinogen }\end{array}$ & NON-Toxicant ${ }^{3}$ & NON-Sensitizer ${ }^{1}$ \\
\hline & Not available & 0.7800 & $\begin{array}{l}\text { NON-Mutagen } \\
\text { (low reliability) }^{1}\end{array}$ & $\begin{array}{c}\text { Mutagen } \\
\text { (low reliability) }\end{array}$ & $\begin{array}{c}\text { NON- } \\
\text { Carcinogen }\end{array}$ & NON-Toxicant $^{3}$ & NON-Sensitizer ${ }^{1}$ \\
\hline & Not available & 1.2600 & $\begin{array}{l}\text { NON-Mutagen } \\
\text { (low reliability) }^{1}\end{array}$ & $\begin{array}{c}\text { Mutagen } \\
\text { (moderate reliability) }\end{array}$ & $\begin{array}{c}\text { NON- } \\
\text { Carcinogen }\end{array}$ & NON-Toxicant $^{1}$ & NON-Sensitizer ${ }^{1}$ \\
\hline & Not available & 1.3000 & $\begin{array}{l}\text { NON-Mutagen } \\
\text { (low reliability) }^{1}\end{array}$ & $\begin{array}{c}\text { Mutagen } \\
\text { (moderate reliability) }^{2}\end{array}$ & $\begin{array}{c}\text { NON- } \\
\text { Carcinogen }\end{array}$ & NON-Toxicant ${ }^{1}$ & NON-Sensitizer ${ }^{1}$ \\
\hline & Not available & 0.0130 & $\begin{array}{l}\text { NON-Mutagen } \\
\text { (low reliability) }^{1}\end{array}$ & $\begin{array}{c}\text { Mutagen } \\
\text { (low reliability) }^{2}\end{array}$ & $\begin{array}{c}\text { NON- } \\
\text { Carcinogen }\end{array}$ & NON-Toxicant ${ }^{3}$ & Sensitizer ${ }^{1}$ \\
\hline & Not available & 0.0010 & $\begin{array}{l}\text { NON-Mutagen } \\
\text { (moderate } \\
\text { reliability) }\end{array}$ & $\begin{array}{c}\text { Mutagen } \\
\text { (moderate reliability) }^{2}\end{array}$ & $\begin{array}{c}\text { NON- } \\
\text { Carcinogen }\end{array}$ & NON-Toxicant ${ }^{3}$ & Sensitizer $^{1}$ \\
\hline & Not available & 0.0020 & $\begin{array}{l}\text { NON-Mutagen } \\
\text { (low reliability) }^{1}\end{array}$ & $\begin{array}{c}\text { Mutagen } \\
\text { (low reliability) }^{2}\end{array}$ & $\begin{array}{c}\text { NON- } \\
\text { Carcinogen }\end{array}$ & NON-Toxicant $^{3}$ & Sensitizer ${ }^{1}$ \\
\hline & Not available & 1.5600 & $\begin{array}{l}\text { NON-Mutagen } \\
\text { (low reliability) }{ }^{1}\end{array}$ & $\begin{array}{c}\text { Mutagen } \\
{\text { (low reliability })^{2}}^{2}\end{array}$ & $\begin{array}{c}\text { NON- } \\
\text { Carcinogen }\end{array}$ & NON-Toxicant ${ }^{3}$ & Sensitizer ${ }^{1}$ \\
\hline
\end{tabular}

*Experimentally-determined minimal inhibitory concentrations $[\mu \mathrm{g} / \mathrm{mL}]$.

1 - accuracy of prediction for similar molecules found in the training set is good.

${ }^{2}$ - accuracy of prediction for similar molecules found in the training set is not optimal.

${ }^{3}$ - accuracy of prediction for similar molecules found in the training set is not adequate. 
Table 2. Compounds Predicted as Non-Toxic by VEGA Platform from the Combinatorial Set of 133 Novel 6-FQ Derivatives Proposed as Drug Candidates for Further Research

\begin{tabular}{|c|c|c|c|c|c|c|}
\hline Compound & MIC $_{\text {pred-combi }}{ }^{*}$ & $\begin{array}{l}\text { Mutagenicity } \\
\text { Model A } \\
\text { Prediction }\end{array}$ & $\begin{array}{l}\text { Mutagenicity } \\
\text { Model B } \\
\text { Prediction }\end{array}$ & $\begin{array}{c}\text { Carcinogenicity } \\
\text { Model (CAESAR) - } \\
\text { Prediction }\end{array}$ & $\begin{array}{c}\text { Developmental Toxicity } \\
\text { Model (CAESAR) - } \\
\text { Prediction }\end{array}$ & $\begin{array}{c}\text { Skin Sensitisation } \\
\text { Model (CAESAR) - } \\
\text { Prediction }\end{array}$ \\
\hline & 0.0021 & $\begin{array}{l}\text { NON-Mutagen } \\
\text { (low reliability) }^{2}\end{array}$ & $\begin{array}{l}\text { NON-Mutagen } \\
\text { (low reliability) }\end{array}$ & NON-Carcinogen ${ }^{1}$ & NON-Toxicant ${ }^{1}$ & NON-Sensitizer ${ }^{2}$ \\
\hline & 0.0021 & $\begin{array}{l}\text { NON-Mutagen } \\
\text { (low reliability) }^{2}\end{array}$ & $\begin{array}{l}\text { NON-Mutagen } \\
\text { (low reliability) }^{3}\end{array}$ & NON-Carcinogen ${ }^{2}$ & NON-Toxicant ${ }^{1}$ & NON-Sensitizer ${ }^{1}$ \\
\hline & 0.0021 & $\begin{array}{l}\text { NON-Mutagen } \\
\text { (low reliability) }^{2}\end{array}$ & $\begin{array}{l}\text { NON-Mutagen } \\
\text { (low reliability) }^{3}\end{array}$ & NON-Carcinogen ${ }^{1}$ & NON-Toxicant ${ }^{1}$ & NON-Sensitizer ${ }^{1}$ \\
\hline & 0.0021 & $\begin{array}{c}\text { NON-Mutagen } \\
\text { (moderate reliability) }{ }^{1}\end{array}$ & $\begin{array}{l}\text { NON-Mutagen } \\
\text { (low reliability) }^{3}\end{array}$ & NON-Carcinogen ${ }^{1}$ & NON-Toxicant ${ }^{1}$ & NON-Sensitizer ${ }^{1}$ \\
\hline & 0.0130 & $\begin{array}{c}\text { NON-Mutagen } \\
\text { (moderate reliability) }\end{array}$ & $\begin{array}{l}\text { NON-Mutagen } \\
\text { (low reliability) }^{3}\end{array}$ & NON-Carcinogen ${ }^{1}$ & NON-Toxicant ${ }^{1}$ & NON-Sensitizer ${ }^{2}$ \\
\hline & 0.0499 & $\begin{array}{l}\text { NON-Mutagen } \\
\text { (low reliability) }^{2}\end{array}$ & $\begin{array}{l}\text { NON-Mutagen } \\
\text { (low reliability) }^{3}\end{array}$ & NON-Carcinogen ${ }^{2}$ & NON-Toxicant ${ }^{1}$ & NON-Sensitizer ${ }^{1}$ \\
\hline & 0.0499 & $\begin{array}{l}\text { NON-Mutagen } \\
\text { (low reliability) }^{2}\end{array}$ & $\begin{array}{l}\text { NON-Mutagen } \\
\text { (low reliability) }^{3}\end{array}$ & NON-Carcinogen ${ }^{1}$ & NON-Toxicant ${ }^{1}$ & NON-Sensitizer ${ }^{1}$ \\
\hline & 0.0499 & $\begin{array}{l}\text { NON-Mutagen } \\
\text { (low reliability) }^{2}\end{array}$ & $\begin{array}{l}\text { NON-Mutagen } \\
\text { (low reliability) }^{3}\end{array}$ & NON-Carcinogen ${ }^{1}$ & NON-Toxicant $t^{3}$ & NON-Sensitizer ${ }^{1}$ \\
\hline & 0.1000 & $\begin{array}{l}\text { NON-Mutagen } \\
\text { (low reliability) }^{1}\end{array}$ & $\begin{array}{l}\text { NON-Mutagen } \\
\text { (low reliability) }^{3}\end{array}$ & NON-Carcinogen ${ }^{1}$ & NON-Toxicant ${ }^{1}$ & NON-Sensitizer ${ }^{1}$ \\
\hline & 0.1000 & $\begin{array}{l}\text { NON-Mutagen } \\
\text { (low reliability) }^{1}\end{array}$ & $\begin{array}{l}\text { NON-Mutagen } \\
\text { (low reliability) }{ }^{2}\end{array}$ & NON-Carcinogen ${ }^{1}$ & NON-Toxicant ${ }^{1}$ & NON-Sensitizer ${ }^{1}$ \\
\hline & 0.1000 & $\begin{array}{c}\text { NON-Mutagen } \\
\text { (moderate reliability) })^{1}\end{array}$ & $\begin{array}{l}\text { NON-Mutagen } \\
\text { (low reliability) }^{3}\end{array}$ & NON-Carcinogen ${ }^{1}$ & NON-Toxicant $t^{3}$ & NON-Sensitizer ${ }^{2}$ \\
\hline
\end{tabular}

*Minimal inhibitory concentration values $[\mu \mathrm{g} / \mathrm{mL}]$ predicted by using our pre-devised CP ANN model $[10,12]$.

${ }^{1}$ - accuracy of prediction for similar molecules found in the training set is good.

$2^{2}$ - accuracy of prediction for similar molecules found in the training set is not optimal.

${ }^{3}$ - accuracy of prediction for similar molecules found in the training set is not adequate. 
and mutagenicity classification model working with two sets of structural alerts are not adequate. There is also one not adequate prediction from carcinogenicity classification model. In Table $\mathbf{1}$ all the predictions are labeled with the accuracy levels (1-3).

Similar analysis was done for the set combinatoriallygenerated 6-FQ drug candidates. Namely, from the total pool of 133 virtual combinatorial 6-FQ derivatives proposed as drug candidates for further research there were more compounds with all toxicity parameters predicted as negative when tested with VEGA platform. Chemical structures and predicted activity values of all non-toxic compounds are presented in Table 2; one can see that there are 11 compounds out of 133 drug candidates with negative toxicity predictions for all endpoints. From the results presented in Table 2 one can see that all compounds predicted as nontoxic consist $\mathrm{CH}$ substituent at $\mathrm{X} 8$ (Scheme 1b); the only exception is the last compound in the list with a more complex substituent. Similarly to the analysis of the experimentally-deteremined compounds represented in Table 1, all proposed drug candidates with low predicted toxicity exhibit low reliability due to applicability domain criterion. Again, few predicted values from mutagenicity classification model show moderate reliability. For all molecules from a set of 133 new 6-FQ derivatives we found that accuracies are good, except for the accuracy of the mutagenicity classification model working with two sets of structural alerts, which is not adequate for almost all compounds.

\section{TOXTREE Expert Knowledge System}

The TOXTREE expert (knowledge) system was applied to assess the toxicity of both data sets studied, the 145 6-FQs with experimentally-determined activities, and the 133 novel combinatorially-generated 6-FQ drug candidates. The results were rather disappointing, because the system was not able to notice any difference in toxicity level for all the assessed chemicals. We have found out that all chemicals in the studied datasets were classified as highly toxic. They belong to Class III, which by definition contains substances with chemical structures that permit no strong initial impression of safety and may even suggest a significant toxicity. If substances are active against bacteria or microorganisms, they are also toxic to human. The chemicals from our dataset are predicted as equally toxic. No priority can be done for further studies. It can be concluded that the TOXTREE expert knowledge system is too sensitive to structural alerts to give us some useful prioritization of drug candidates regarding their potential toxicity.

\section{SUMMARY}

With in silico studies of the quinolone antibacterials against $M$. tuberculosis a set of 133 new 6-FQ derivatives was proposed as drug candidates for further research and development. A structure side-effects relationship (SSER) study for prediction of their toxicological profile was performed by using publicly available knowledge-based (expert) systems and QSAR models. CAESAR models and TOXTREE expert system were applied for the in silico tests.
With the TOXTREE expert (knowledge) system we have found that all 133 proposed novel combinatorial 6-FQ derivatives in the studied dataset belong to Class III, which by definition contains substances with chemical structures that permit no strong initial impression of safety and may even suggest a significant toxicity. Since we were not able to distinguish the chemicals in our datasets using the TOXTREE toxicity classification results, we did not find TOXTREE appropriate for the prioritization purposes in drug design of the 6-FQ derivatives.

The results from CAESAR models were more helpful for our purpose. The toxicity parameters for skin sensitization, carcinogenicity, mutagenicity and developmental toxicity were assessed. We have identified 11 compounds out of 133 novel combinatorial 6-FQ derivatives proposed as drug candidates that were predicted as non-toxic. These potentially non-toxic new 6-FQ derivatives could be good candidates for clinical studies. Interestingly, from the set of 145 6-FQs with experimentally-determined antibacterial activity that were used for training of our QSAR model and contained several commercially available drugs, we found only one compound that was predicted as non-toxic for all five toxicity endpoints. Consequently, we can anticipate that 11 new 6-FQ derivatives with high anti-mycobacterial activity predicted by our model will have less harmful side effects than several existing drugs.

$$
\begin{aligned}
& \text { ABBREVIATIONS } \\
& \text { 6-FQ = 6-fluoroquinolones } \\
& \mathrm{BCF}=\text { Bioconcentration factor } \\
& \mathrm{CP} \text { ANN = Counter Propagation Artificial Neural Network } \\
& \text { FDA }=\text { Food and Drug Administration } \\
& \mathrm{LC}_{50}=\text { lethal concentration, } 50 \% \\
& \text { OECD = Organisation for Economic Co-operation and } \\
& \text { Development } \\
& \text { QSAR = quantitative structure-activity relationship } \\
& \text { RBFNN = Radial Basis Function Neural Networks } \\
& \mathrm{REACH}=\text { Registration, Evaluation and Authorization and } \\
& \text { Restriction of Chemicals } \\
& \text { SAR = structure-activity relationship } \\
& \text { SSER = structure side-effects relationship } \\
& \text { SVM = Support Vector Machine } \\
& \text { T.E.S.T. }=\text { Toxicity Estimation Software Tool } \\
& \text { TB }=\text { Tuberculosis }
\end{aligned}
$$

\section{CONFLICT OF INTEREST}

The authors declare that they have no competing interests.

\section{ACKNOWLEDGEMENTS}

Financial support of the Ministry of Education, Science, Culture and Sport of the Republic of Slovenia through the research grant P1-0017 is gratefully acknowledged. 


\section{PATIENT'S CONSENT}

Declared none.

\section{REFERENCES}

[1] Lesher GY, Froelich ED, Gruet MD, Bailey JH, Brundage RF. 1,8 Naphthyridine derivatives. A new class of chemotherapeutic agents. J Med Pharm Chem 1962; 5: 1063-8.

[2] Koga H, Itoh A, Murayama S, Suzue S, Irikura T. Structureactivity relationships of antibacterial 6,7- and 7,8-disubstituted 1alkyl-1,4-dihydro-4-oxoquinolone-3-carboxylic acids. J Med Chem 1980; 23: 1358-63.

[3] Mitscher LA, Devasthale PV, Zavod RM. Structure-activity relationships. In: Hooper DC, Wolfson JS (eds) Quinolone antimicrobial agents. Washington DC, American Society for Microbiology, 2nd edn. 1993: 3-51.

[4] Domagala JM. Structure-activity and structure-side-effect relationships for the quinolone antibacterials. J Antimicrob Chemother 1994; 33:685-706.

[5] Renau TE, Gage JW, Dever JA, Roland GE, Joannides ET, Shapiro MA, Sanchez JP, Gracheck SJ, Domagala JM, Jacobs MR, Reynolds RC. Structure-activity relationships of quinolone agents against mycobacteria: effect of structural modifications at the 8 position. Antimicrob Agents Chemother 1996; 40: 2363-8.

[6] Sanchez JP, Gogliotti RD, Domagala JM, Gracheck SJ, Huband MD, Sesnie JA, Cohen MA, Shapiro MA. The synthesis, structureactivity, and structure-side effect relationships of a series of 8alkoxy- and 5-amino-8-alkoxyquinolone antibacterial agents. J Med Chem 1995; 38: 4478-87.

[7] Tillotson, GS. Quinolones: Structure-activity relationship and future predictions. J Med Microbiol 1996; 44: 320-4.

[8] Sharma PC, Jain A, Jain S. Fluoroquinolone antibacterials: a review on chemistry, microbiology and therapeutic prospects. Acta Pol Pharm 2009; 66: 587-604.

[9] NIAID-Division of AIDS, NIH/OI/TB Therapeutics Database. http://chemdb2.niaid.nih.gov.
[10] Minovski N, Vračko M, Šolmajer T. Quantitative structure-activity relationship study of antitubercular fluoroquinolones. Mol Divers 2011; 15: 417-26.

[11] Minovski N, Šlmajer T. Chemometrical exploration of combinatorially generated drug-like space of 6-fluoroquinolone analogs : a QSAR study. Acta Chim Slov 2010; 57: 529-40.

[12] Minovski N, Perdih A, Solmajer T. Combinatorially-generated library of 6-fluoroquinolone analogs as potential novel antitubercular agents : a chemometric and molecular modeling assessment. J Mol Model 2012; 18: 1735-53.

[13] Benfenati E. The CAESAR project for in silico models for the REACH legislation. Chemistry Central Journal 2010; 4(Suppl. 1):I1. Available at: http://www.journal.chemistrycentral.com/conte nt/4/S1/I1. Accessed: July 2012.

[14] Fjodorova N, Vračko M, Novič M, Roncaglioni A, and Benfenati E. New public QSAR model for carcinogenicity. Chemistry Central Journal 2010; 4 (Suppl 1):S3. Avalable at: http://www.journal.ch emistrycentral.com/content/4/S1/S3. Accessed: July 2012.

[15] http://www.caesar-project.eu/. Accessed: July 2012.

[16] http://www.vega-qsar.eu/. Accessed: July 2012.

[17] Enoch SJ, Cronin MT, Schultz TW, Madden JC. Quantitative and mechanistic read across for predicting the skin sensitization potential of alkenes acting via Michael addition. Chem Res Toxicol 2008; 21: 513-20.

[18] Ferrari T, Gini G, Golbamaki Bakhtyari N, Benfenati E. Mining toxicity structural alerts from SMILES: a new way to derive structure activity relationships. CIDM - IEEE Symposium Series on Computational Intelligence, Paris, April 11-15, 2011.

[19] Patlewicz G, Jeliazkova N, Safford RJ, Worth AP, Aleksiev B. An evaluation of the implementation of the Cramer classification scheme in the Toxtree software. SAR QSAR Environ Res 2008; 19: 495-524.

[20] http://ihcp.jrc.ec.europa.eu/our_labs/computational_toxicology/qsar_too 1s/toxtree/. Accessed: July 2012.

[21] http://toxtree.sourceforge.net/. Accessed: July 2012. 